\title{
Current status of the irritable bowel syndrome
}

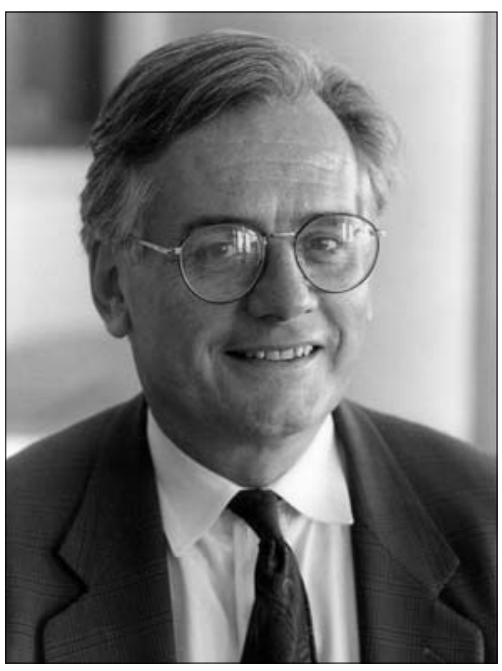

The symposium supplement is based was held in Montreal in October, 1997. I thank the original sponsor of the event, Jouveinal, as well as Parke Davis-Warner Lambert and Axcan Pharma for making the symposium possible.

The symposium focused on tangible processes that may lead to gastrointestinal dysfunctions and, thus, symptom generation in the irritable bowel syndrome (IBS). This focus deliberately excluded psychosocial factors and issues of symptom classification that have dominated the IBS literature for over a decade. It is my belief that, while psychosocial issues are important in the management of some patients with IBS, they do not apply to all IBS patients. I believe that there is a strong need to better understand gastrointestinal dysfunction in IBS in order to develop more efficacious treatments than those that currently exist. Gastrointestinal dysfunction is traditionally overlooked in the psychological models of IBS.

It has been known for some time that there are no motility patterns that are specific for IBS and that drugs aimed at influencing gastrointestinal motility do not benefit all patients. As our understanding of the integrative nature of gut physiology has increased, other putative processes of symptom development have emerged, including visceral hypersensitivity (hyperalgesia) and autonomic imbalance. In addition, it is now recognized that IBS develops in about a third of patients following enteric infection, and, as in asthma, we must explore low grade inflammation and the postinflammatory state of the gut to gain insights into this subpopulation of IBS patients.

This supplement, therefore, contains important state of the art discussions - not only on motor function in IBS, but also on how it is modulated by stress and by low grade inflammatory processes - by Drs Camilleri (pages 8A-11A), Plourde (pages 26A-31A), Taché et al (pages 18A-25A) and myself (pages 47A-49A). There is a comprehensive update of current and future treatments of altered motility by Drs Scarpignato and Pelosini (pages 50A-65A). Considerable attention is paid to sensory physiology (Drs Gebhart [pages 37A-41A] and Azpiroz [pages 12A-14A]), and how it may be perturbed by stress (Dr Delvaux [pages 32A-36A]) and inflammation (Drs Bueno and Fioramonti [pages 42A-46A]), and modulated by autonomic tone (Dr Tougas [pages 15A-17A]). This field is ripe for therapeutic exploitation, and a number of potential avenues are discussed (Dr Mayer et al [pages 66A-70A]). The first breakthrough compound in the treatment of visceral hyperalgesia was the kappa opiate fedotozine; this and other opiates are discussed (Dr Corazziari [pages 71A-75A]). The issue of IBS in children and its relation to adult IBS is discussed because many of the potential therapeutic avenues will apply to the pediatric populations (Dr Milla [pages 76A-84A]).

Finally, I believe that there is an urgent need to document the economic burden of IBS in our society because this condition, in my opinion, has lacked medicoscientific respectability in the past. This, in part, reflects the difficulties in describing and documenting the problems related to IBS, and underestimates its impact, which negatively influences patients' claims for support, the research funding level and the development of drugs for this common and problematic condition.

I thank all of the participants of this meeting for their contributions, both to the symposium and to this supplement.

\footnotetext{
Division of Gastroenterology, and Intestinal Diseases Research Program, Faculty of Health Sciences and The Hamilton Health Sciences Corporation, Hamilton, Ontario

Correspondence: Dr SM Collins, Division of Gastroenterology, Room 4W8, McMaster University Medical Centre, Hamilton, Ontario L8N 325. Telephone 905-521-2100 ext 5255, fax 905-521-4958, e-mail scollins@fhs.mcmaster.ca
} 


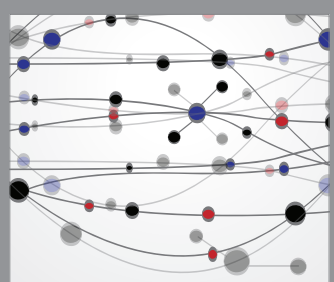

The Scientific World Journal
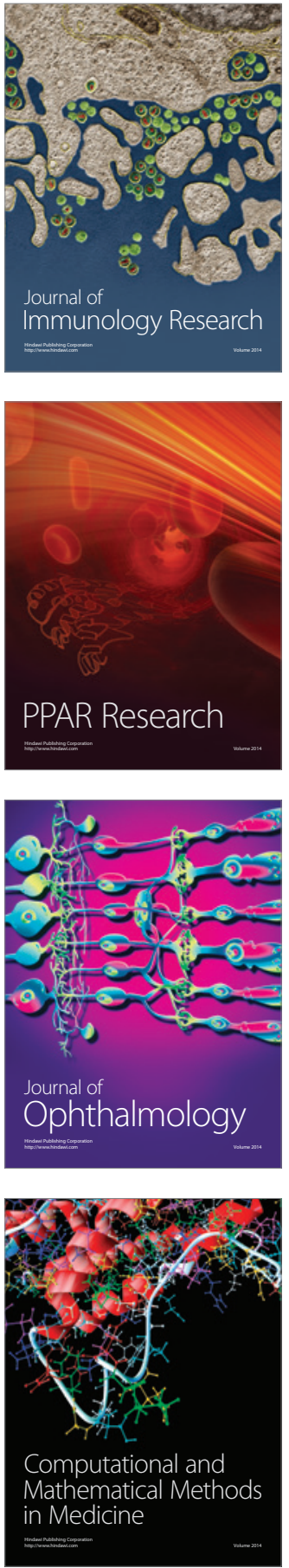

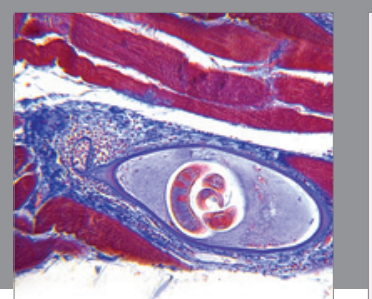

Gastroenterology Research and Practice

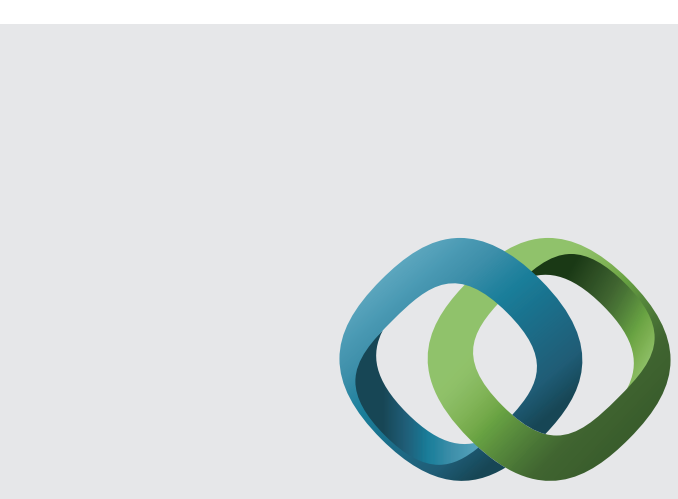

\section{Hindawi}

Submit your manuscripts at

http://www.hindawi.com
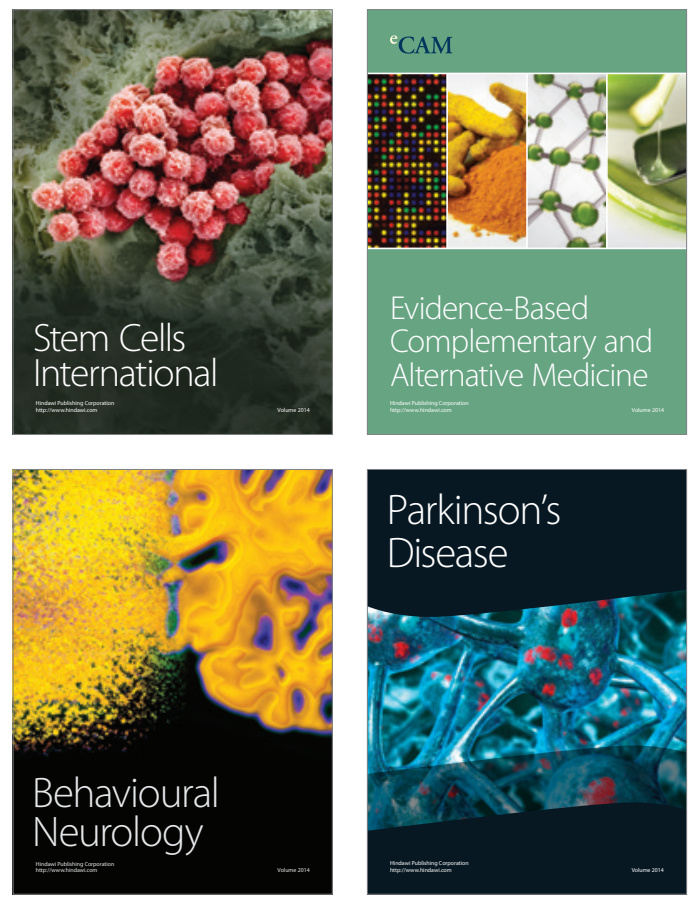
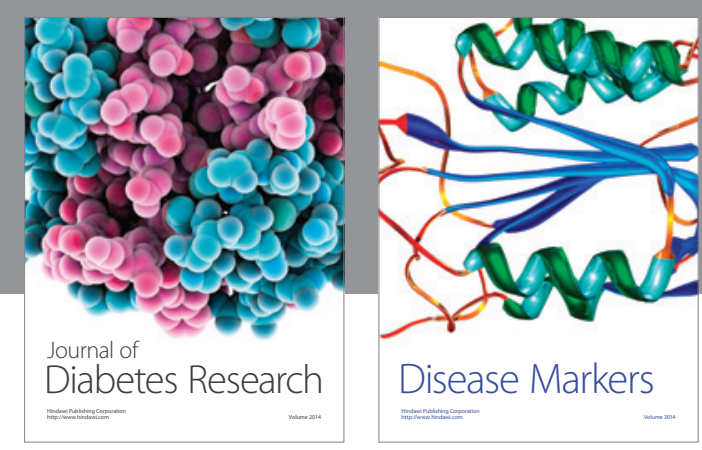

Disease Markers
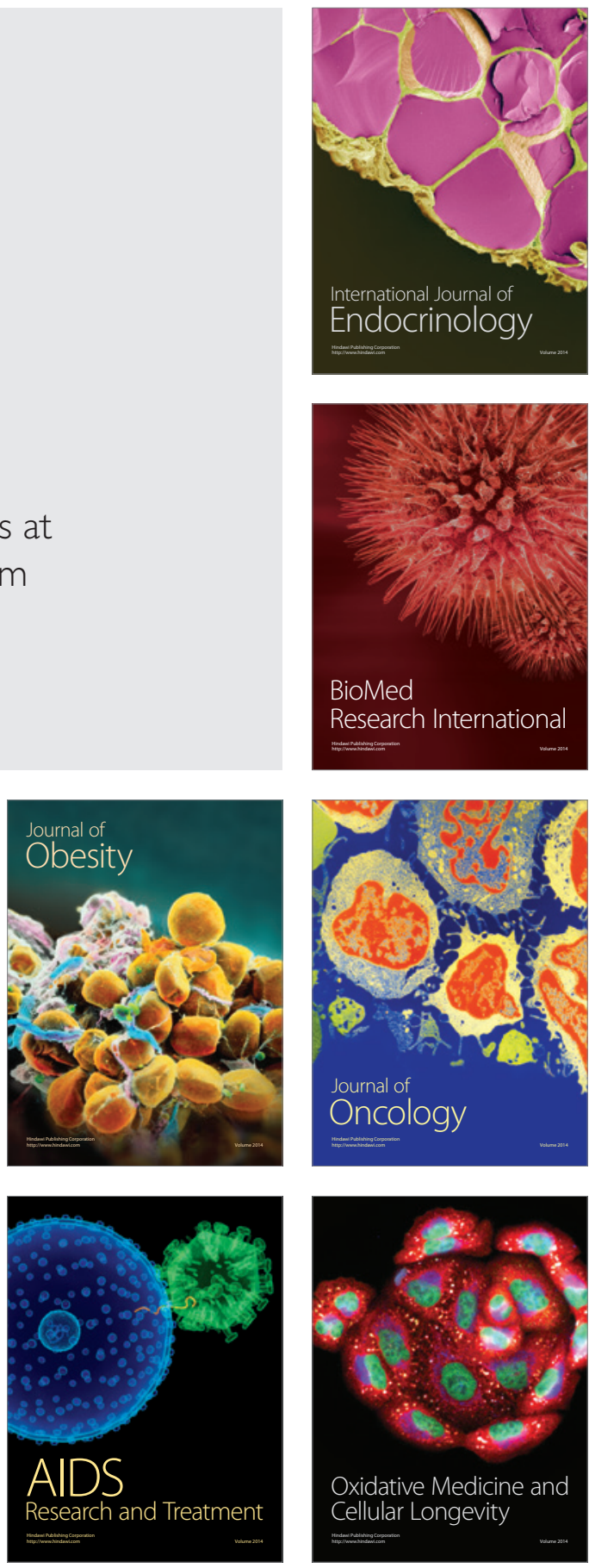